\title{
On the Contribution of Grain Boundary Sliding to Firn Densification - an Assessment using an Optimisation Approach
}

\author{
Timm Schultz ${ }^{1}$, Ralf Müller ${ }^{1}$, Dietmar Gross ${ }^{2}$, and Angelika Humbert ${ }^{3,4}$ \\ ${ }^{1}$ Institute of Applied Mechanics, Technische Universität Kaiserslautern, Kaiserslautern, Germany \\ ${ }^{2}$ Division of Solid Mechanics, Technische Universität Darmstadt, Darmstadt, Germany \\ ${ }^{3}$ Alfred-Wegener-Institut Helmholtz-Zentrum für Polar- und Meeresforschung, Bremerhaven, Germany \\ ${ }^{4}$ Faculty of Geosciences, University of Bremen, Bremen, Germany
}

Correspondence: Timm Schultz (tschultz@rhrk.uni-kl.de)

\begin{abstract}
Physics based simulation approaches to firn densification often rely on the assumption that grain boundary sliding, first introduced by Alley (1987) to firn, is the leading process driving the first stage of densification. However, often so called semi empirical models are favored against the description of grain boundary sliding due to simplicity and uncertainties regarding model parameters. In this study, we are assessing the applicability of grain boundary sliding to firn using a numeric firn densification model and an optimisation approach, for which we formulate variants of the constitutive relation by Alley (1987). The efficient model implementation based on an updated Lagrangian numerical scheme enables us to perform a large number of simulations testing different model parameters, to find simulation results suiting 159 firn density profiles from Greenland and Antarctica best. For most of the investigated locations a good agreement of simulated and measured firn density profiles was found. This implies that the constitutive relation by Alley (1987) characterises the fist stage of firn densification well, if suitable model parameter are used. An analysis of the parameters that lead to best matches reveals a dependency on the mean surface mass balance. This may indicate an insufficient description of the load situation, as horizontal components of the stress tensor are usually neglected in one dimensional models of the firn column.
\end{abstract}

\section{Introduction}

The modelling of firn densification is of large interest for a couple of research fields: (i) knowledge of the time of pore close-off is relevant for climate reconstructions using ice cores. (ii) Depth density profiles and their annual variation is a prerequisite to transfer remote sensing elevation change into mass change, hence sea level contribution of ice sheets. (iii) The density of firn is governing the melt water retention in firn in areas where significant surface melt occurs. With increasing melt in Greenland, knowledge of firn density is becoming an urgent issue. An adequate firn densification model is thus a challenge to tackle.

Two basic categories of firn densification models can be identified. The first and greater one is following the so called semi empirical concept of Herron and Langway (1980), which itself is based on Sorge's Law (Bader, 1954) and the Robin Hypothesis 
(Robin, 1958). This approach relates the densification rate in firn to accumulation, but neglects the actual overburden stress acting on the firn. Different models expand this relation in different ways to include effects of temperature, accumulation rate and grain size. Examples are the models by Arthern et al. (2010), Ligtenberg et al. (2011) and Simonsen et al. (2013). Typically empirical parameters of these models are adjusted to certain datasets of depth density profiles.

The second category of firn densification models tries to quantify the physical processes related to the densification of firn. These processes incorporate different types of creep and diffusion. Micro mechanical models are used for small scale investigations (Johnson and Hopkins, 2005; Theile et al., 2011; Fourtenau et al., 2020) while continuum mechanics based models can be used for large scale simulations. Examples of the latter are models by Arthern and Wingham (1998), Arnaud et al. (2000) and Goujon et al. (2003). These models again are based on the concepts first introduced by Maeno and Ebinuma (1983) who adopted modelling approaches from sintering theory, developed in the field of metallurgy, to firn.

The theory of hot isostatic pressing, which applies for firn (Maeno and Ebinuma, 1983), is formulated for well compacted powders as used for many purposes in industry (eg. Kang, 2005). However, the densification of firn starts with far less regular grain geometries and conglomerates of grains. Therefore the first stage of firn densification, namely up to the critical density of $\rho_{c}=550 \mathrm{~kg} \mathrm{~m}^{-3}$ (Herron and Langway, 1980), has to be described by other processes.

Alley (1987) first applied grain boundary sliding, adopted from Raj and Ashby (1971), to firn densification at low density. Since then the description of this process was used in various other firn densification models (Arthern and Wingham, 1998; Arnaud et al., 2000; Goujon et al., 2003; Bréant et al., 2017). Nevertheless, the assumption that grain boundary sliding is the dominant process in firn densification at densities below $\rho_{c}=550 \mathrm{~kg} \mathrm{~m}^{-3}$ was questioned numerous times. For example Theile et al. (2011), by conducting experiments on a small number of snow samples, tried to point out that the densification is more likely driven by processes within the grain than by the inter granular process of grain boundary sliding.

When Alley (1987) first published the description of grain boundary sliding for firn, he tested the material model by fitting the model results to four firn profiles available at this time, evaluating the resulting model parameters. As indicated by the title of his paper and pointed out in its discussion, grain boundary sliding might not be the only process driving the densification of firn at low density and model parameters might differ, but by using the given constitutive law it is possible to recreate measured depth density profiles to a satisfying degree.

In this study we aim at evaluating whether grain boundary sliding and its description is suitable for the simulation of firn densification at low density. In the sense of Alley (1987) we compare model results to measured data. In contrast to Alley (1987) the amount of available data became much larger. Alongside to a large number of firn profiles this includes forcing data which, together with additional modelling techniques, allows us to simulate firn profiles at a very high quality.

\section{Methods}

In order to test the description of grain boundary sliding by Alley (1987) we use a numeric model, simulating the evolution of a one dimensional firn column with respect to time. The model incorporates variants of the constitutive relation of Alley (1987), all of which combine several model parameters in a single factor. We then force the model with data provided by the 
regional climate model RACMO2.3 (Van Wessem et al., 2014; Noël et al., 2015), representing the climate of the last decades at 159 different locations where firn density measurements were retrieved. These firn measurements are available through the "Surface Mass Balance and Snow Depth on Sea Ice Working Group (SUMup) snow density subdataset" (Koenig and Montgomery, 2019). By varying the factor incorporated in the variants of the constitutive equation, we produce a large number of simulation results, which are compared to the corresponding density measurements. The quality of tested factors reflects in the deviation between model results and measurements. Evaluating factor values leading to best results, reveals possible improvements in the description of grain boundary sliding for firn densification at low density. In the following sections the model, the optimisation scheme and the used density and forcing data are described.

\section{Model description}

\subsection{Numerical Treatment of Densification}

All model equations are solved on an adapting one dimensional grid, updated in every time step. The approach follows the concept of an updated Lagrangian description with the update velocity being the flow velocity. This results in material fixed coordinates. The Lagrangian like description allows for a very high spatial and temporal resolution in the simulations. It can be shown that integrating the local Eulerian form of the mass balance in one dimension over a material control volume with moving boundaries $z_{1}(t)$ and $z_{2}(t)$ leads to (Ferziger and Perić, 2002):

$70 \frac{d}{d t} \int_{z_{1}(t)}^{z_{2}(t)} \rho d z+\int_{z_{1}(t)}^{z_{2}(t)} \frac{\partial}{\partial z}\left(\rho\left(v-v_{b}\right)\right) d z=0$.

Here $\rho$ describes the density, $z$ the vertical coordinate, $t$ the time and $v$ is the flow velocity, whereas $v_{b}$ represents the velocity of the grid or integration boundary. When the boundary velocity equals the material velocity $v_{b}=v$, the second part of Equation (1), describing advection, vanishes. The resulting equation is equal to the Lagrangian form of the mass balance (Ferziger and Perić, 2002). On a one dimensional grid, build up by a number of grid points, as illustrated in Fig. 1, we define the grid point velocity to be $v_{b}$ and to equal the flow velocity $v_{b} \equiv v$. The location of all grid points is updated in every time step by integrating the grid point velocity using a forward Euler scheme. In this way advection is entirely represented by the adapting grid.

The grid point velocity is calculated using the constitutive equation of grain boundary sliding as described in Section 3.2 and the definition of the strain rate in one dimension. The description of grain boundary sliding provides the strain rate in vertical direction along the grid $\dot{\varepsilon}_{z z}$ as a function of the vertical stress $t_{z z}$, density $\rho$, temperature $T$ and grain radius $r$

$\dot{\varepsilon}_{z z}=f\left(t_{z z}, \rho, T, r\right)=\frac{\partial v}{\partial z}=\frac{\partial v_{b}}{\partial z}$.

The strain rate of a material line element can be defined as the spatial derivative of the velocity as shown in Equation (2) (Haupt, 2002). On a one dimensional grid, defined by a number of grid points, the space between neighbouring grid points can 


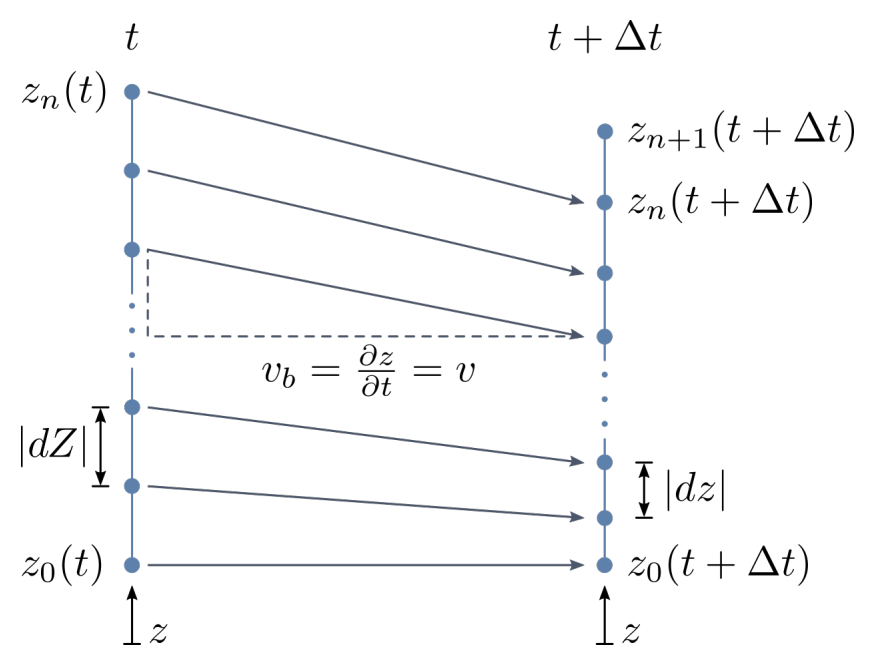

Figure 1. Principle of the grid evolution. On the left side a grid at time $t$ is shown. The updated grid at time $t+\Delta t$ is illustrated on the right hand side of the figure. The grid points move with the grid point velocity $v_{b}$ which equals to flow velocity $v$. At time $t+\Delta t$ an additional grid point $z_{n+1}$ representing accumulation is added. Distances between neighbouring grid points can be understood as material line elements $|d Z|$ and $|d z|$ in the reference and in the current configuration respectively.

be considered as a material line element (see Fig. 1). Therefore the grid point velocity $v_{b}$ can easily be computed by integrating the strain rate $\dot{\varepsilon}_{z z}$ in vertical direction along the length of the grid cell:

$v_{b}=\int_{z_{1}}^{z_{2}} \dot{\varepsilon}_{z z} d z$

For the implementation of Equation (3) an integration constant determined by a suitable boundary condition is needed. It is reasonable to apply a Dirichlet boundary condition, forcing the grid point velocity to be zero, at either the top or the base of the computational domain, representing a fixed reference point at the top or the base of the modelled firn profile, respectively. All other points defining the adapting grid are moving with respect to this anchor point. In case of the present study we decided to place the anchor point at the base of the simulated firn profiles ( $z_{0}$ in Fig. 1). Depth coordinates of profiles shown in following figures were adjusted for better readability.

For the representation of accumulation at the top of a simulated firn profile an inflow boundary condition has to be implemented. To achieve this, in every time step an additional grid point is added at the top of the grid. Its coordinate within the grid $z_{n+1}(t+\Delta t)$ is calculated by

$z_{n+1}(t+\Delta t)=z_{n}(t+\Delta t)+\Delta t a_{0}(t) \frac{\rho_{\mathrm{water}}}{\rho_{0}}$

with $a_{0}$ the accumulation rate given in $\mathrm{ms}^{-1}$ water equivalent, $\Delta t$ the length of the time step, $\rho_{\text {water }}$ the density of water and $\rho_{0}$ the density of the deposited snow. The position of a new grid point $\left(z_{n+1}(t+\Delta t)\right.$ in Fig. 1) is the position of the firn 
surface at the last time step $z_{n}$ plus the thickness of the firn layer deposited during the last time step. This thickness is defined by the time time step $\Delta t$ and the time dependent accumulation rate $a_{0}(t)$. As we use an accumulation rate given in the unit of meter water equivalent per second, it has to be converted to the unit of meter firn equivalent taking the site specific surface firn density $\rho_{0}$ and water density $\rho_{\text {water }}$ into account.

\subsection{Grain Boundary Sliding}

Equation (5) shows the constitutive law by Alley (1987), describing the process of grain boundary sliding. In the following the different components and characteristics of the equation will be explained briefly.

$\dot{\varepsilon}_{z z}=-\frac{2}{15} \quad \delta_{b} \frac{8 D_{\mathrm{BD}} \Omega}{k_{b} T h^{2}} \quad \frac{1}{r \mu^{2}} \quad\left(\frac{\rho_{\text {ice }}}{\rho}\right)^{3} \quad\left(1-\frac{5}{3} \frac{\rho}{\rho_{\text {ice }}}\right) \quad t_{z z}$

The factor of $2 / 15$, seeming arbitrary at first, results from the geometric deviation pointed out by Alley (1987). Another geometric parameter $\delta_{b}$ describes the width of the grain boundary. The following term describes the reciprocal bond viscosity (Raj and Ashby, 1971) where $\Omega$ stands for the volume of the $\mathrm{H}_{2} \mathrm{O}$ molecule, $k_{b}$ is the Boltzmann constant, $T$ resembles the temperature and $h$ describes the amplitude of the grain boundary obstructions, a measure for the roughness of the grain boundaries. The coefficient $D_{\mathrm{BD}}$ is given by an Arrhenius law describing the rate of boundary diffusion depending on the temperature. Corresponding values for the activation energy and a prefactor have to be provided.

The strain-rate resulting from grain boundary sliding also depends on the grain radius $r$. The ratio of grain radius to neck radius $\mu$ was introduced by Arthern and Wingham (1998) and is assumed to be constant. The next factor of Equation (5) describes the dependency on the inverse relative density to the power of three. The characteristics of the depth density profiles resulting from the model description are greatly influenced by this and the following term of the constitutive law. The factor of $5 / 3$ corresponds to the inverse relative density of $\rho_{c}=550 \mathrm{~kg} \mathrm{~m}^{-3}$, resulting in a kind of fade out behaviour ending with a strain rate of zero when reaching this critical density.

Finally the stress in vertical direction $t_{z z}$ resulting from the overburden firn is driving grain boundary sliding. The other physical properties influencing the process are density $\rho$, temperature $T$, and grain size $r$.

\subsection{Stress}

For the evaluation of the stress in vertical direction $t_{z z}$ we use the local form of the static linear momentum balance in its Eulerian description. We neglect the acceleration term, as changes in velocity are assumed to be small, leading to

$$
\frac{\partial t_{z z}}{\partial z}+\rho g=0
$$

Computation of the stress $t_{z z}$ can easily be achieved by integrating the product of density $\rho$ and acceleration due to gravity $g$ along the simulated profile. We assume the surface of the profile to be traction free. 


\subsection{Density}

As pointed out in Section 3.1 and illustrated by Equation (1) the change of the density integrated over a test volume with respect to time has to be zero. Or in other words, the mass incorporated in a material control volume cannot change. As the position of the grid points, and therefore the material control volume, does change, the density is changing accordingly. The evaluation of the density integral over a control volume at two time steps leads to

$\rho(t)\left(z_{2}(t)-z_{1}(t)\right)=\rho(t+\Delta t)\left(z_{2}(t+\Delta t)-z_{1}(t+\Delta t)\right)$.

As the space between two neighbouring grid points can be understood as a material line element (Haupt, 2002), Equation (7) can be rewritten in the form of Equation (8). Where $|d Z|=\left|z_{2}(t)-z_{1}(t)\right|$ and $|d z|=\left|z_{2}(t+\Delta t)-z_{1}(t+\Delta t)\right|$ are the lengths of a material line element in the reference configuration and its image in the current configuration respectively:

$\rho(t)|d Z|=\rho(t+\Delta t)|d z|$

Sorting Equation (8) leads to the formulation of the density change with respect to time depending on the definition of the strain $\varepsilon_{z z}$ in one dimension (Haupt, 2002)

$\rho(t+\Delta t)-\rho(t)=-\rho(t+\Delta t)\left(\frac{|d z|-|d Z|}{|d Z|}\right)=-\rho \varepsilon_{z z}$.

140 The evolution of density can therefore be computed by integration of the strain rate $\dot{\varepsilon}_{z z}$ (Section 3.2) in time.

\subsection{Temperature}

As pointed out in Section 3.1 all advection in the model domain is represented by the moving grid the model is discretized by. Therefore the description of temperature evolution reduces to simple heat diffusion:

$\rho c_{p}\left(\frac{\partial T}{\partial t}\right)+\frac{\partial}{\partial z}\left(k(\rho) \frac{\partial T}{\partial z}\right)=0$.

145 Following Paterson (1994), we assume a constant heat capacity of $c_{p}=2009 \mathrm{~J} \mathrm{~kg}^{-1} \mathrm{~K}^{-1}$ and a density dependent thermal conductivity, described by

$k(\rho)=2.1\left(\frac{\rho}{\rho_{\text {ice }}}\right)^{2} \mathrm{~W} \mathrm{~m}^{-1} \mathrm{~K}^{-1}$.

\subsection{Grain Size}

To describe the evolution of grain size we use the well known description of Stephenson (1967) and Gow (1969) as given in Arthern et al. (2010) for mean grain radius $r$ rather than for mean grain cross-sectional area. This is suitable as the grain radius is used in the constitutive equation by Alley (1987). It is written in differential form by

$\frac{\partial r^{2}}{\partial t}=k_{0} \exp \left(-\frac{E_{g}}{R T}\right)$ 
The square of the grain radius increases with a rate in the form of an Arrhenius law, where $R$ is the gas constant and $T$ represents the absolute temperature. Values for the activation energy $E_{g}=42.4 \mathrm{~kJ} \mathrm{~mol}^{-1}$ of the process and the corresponding pre-factor $k_{0}=1.3 \times 10^{-7} \mathrm{~m}^{2} \mathrm{~s}^{-1}$ were adapted from Arthern et al. (2010) following Paterson (1994). In contrast to Arthern et al. (2010) we do not use the mean annual temperature but the actual temperature $T(z, t)$ along the simulated profile.

\subsection{Age}

For reasons of comparison (Section 5.2) and general interest additionally the firn age $\chi$ is simulated. Again due to the fact that advection is represented by the adapting grid, the description is very simple. It is calculated from

$160 \frac{\partial \chi}{\partial t}=1$

New deposited snow has an age of zero, prescribed in the form of a Dirichlet boundary condition. The age discretized at the grid points then increases according to the time step.

\subsection{Time Discretisation}

Time is discretised using constant time steps. For this study 48 time steps per year have shown to be a good compromise between simulation costs and resolution and was used throughout all simulations. The grid resolution depends on the time step as a new grid point is generated in every time step representing accumulation as described in Section 3.1 and shown in Equation (4). Time dependent properties such as the density, temperature, grain size and age were developed using an explicit Euler scheme.

\section{Optimisation}

170 To test the concept of the material model developed by Alley (1987) we vary Equation (5) as it is described in Section 3.2 and compare corresponding model results to density measurements of various firn cores. Variants of the constitutive equation (Equations (14) to (17)) preserve its general form, but group several material parameters into a single factor. Arnaud et al. (2000), Goujon et al. (2003) as well as Bréant et al. (2017) also summed the material parameters of the model by Alley (1987) up into a single parameter. In the study by Bréant et al. (2017) additionally the factor of $5 / 3$ was modified to change the fade out behaviour (see Section 3.2) of the constitutive equation. In the following the four variants, indicated by the subscripts $(\cdot)_{\mathrm{v}_{1}}$ to $(\cdot)_{\mathrm{v}_{4}}$, are shown:

$$
\begin{aligned}
& \dot{\varepsilon}_{z z \mathrm{v}_{1}}=-C_{\mathrm{v}_{1}} D_{\mathrm{BD}} \frac{1}{T} \frac{1}{r}\left(\frac{\rho_{\mathrm{ice}}}{\rho}\right)^{3}\left(1-\frac{5}{3} \frac{\rho}{\rho_{\mathrm{ice}}}\right) t_{z z} \quad, \quad D_{\mathrm{BD}}=A \exp \left(-\frac{Q}{R T}\right), \\
& \dot{\varepsilon}_{z z \mathrm{v}_{2}}=-C_{\mathrm{v}_{2}} D_{\mathrm{BD}} \frac{1}{T} \frac{1}{r}\left(\frac{\rho_{\text {ice }}}{\rho}\right)^{3}\left(1+\frac{0.5}{6}-\frac{5}{3} \frac{\rho}{\rho_{\text {ice }}}\right) t_{z z} \quad, \quad D_{\mathrm{BD}}=A \exp \left(-\frac{Q}{R T}\right) .
\end{aligned}
$$


Variant 1 (Equation (14)) and Variant 2 (Equation (15)) of the constitutive equation combine all material constants using the factors $C_{\mathrm{v}_{1}}$ and $C_{\mathrm{v}_{2}}$, respectively. Excluded from the factor is the Arrhenius law for $D_{\mathrm{BD}}$ with its activation energy $Q$ and the corresponding pre-factor $A$. To preserve the additional dependency on the temperature $T$ constant values of $A=3.0 \times 10^{-2} \mathrm{~m}^{2} \mathrm{~s}^{-1}$ and $Q=44.1 \mathrm{~kJ} \mathrm{~mol}^{-1}$ are used (Alley, 1987; Paterson, 1994; Arthern and Wingham, 1998). Except for the temperature $T$, the vertical strain rate $\dot{\varepsilon}_{z z}$ only depends on the firn density $\rho$, the grain radius $r$ and the stress in vertical direction $t_{z z}$. Variant 2 differs from Variant 1 by the use of the modified fade out factor introduced by Bréant et al. (2017), leading to a theoretical fade out of grain boundary sliding at a density of $\rho_{c}^{*}=596 \mathrm{~kg} \mathrm{~m}^{-3}$.

To test its influence, Variants 3 and 4, given in Equations (16) and (17), disregard the Arrhenius law:

$\dot{\varepsilon}_{z z \mathrm{v}_{3}}=-C_{\mathrm{v}_{3}} \frac{1}{T} \frac{1}{r}\left(\frac{\rho_{\text {ice }}}{\rho}\right)^{3}\left(1-\frac{5}{3} \frac{\rho}{\rho_{\text {ice }}}\right) t_{z z}$,

$\dot{\varepsilon}_{z z \mathrm{v}_{4}}=-C_{\mathrm{v}_{4}} \frac{1}{T} \frac{1}{r}\left(\frac{\rho_{\text {ice }}}{\rho}\right)^{3}\left(1+\frac{0.5}{6}-\frac{5}{3} \frac{\rho}{\rho_{\text {ice }}}\right) t_{z z}$

A possible dependency on the temperature $T$ should reflect in the optimal values of the factors $C_{\mathrm{v}_{3}}$ and $C_{\mathrm{v}_{4}}$. Again in Variant 4 the fade out modification by Bréant et al. (2017) is used while Variant 3 incorporates the original formulation by Alley (1987).

Aim of the optimisation is to find optimal values of the factors $C_{\mathrm{v}_{\mathrm{i}}}$ for every variant of the constitutive relation (Equations (14) to (17)) resulting in a simulated density profile that resembles the measured profiles in the best possible way. As an example, we explain the optimisation process for one selected firn core in more detail. The upper part of ice core ngt03C93.2 (Wilhelms, 2000) is shown in Fig. 2 (a).

Every simulation starts with a spin up in which constant values are used for the forcing. When steady state is reached, a transient run using evolving forcing data follows. The forcing at the location of ngt03C93.2 is shown in Fig. 2 (c). The resulting firn profile is then compared to the measured profile. Unlike other recent studies (Lundin et al., 2017; Verjans et al., 2020) we use the objective measure of the root mean square deviation between measured and modelled density, which allows a simple and good comparability between the simulation result and the density measurement. To calculate the deviation, simulated density values are interpolated linearly to the measurement locations along the profile. To guarantee a high quality of the results, we restrict the calculation of the deviation to the domain defined by the surface and the oldest horizon within the firn profile affected by the forcing. In case of ngt03C9.2 this horizon is the surface of 1958 at a depth of approximately $11 \mathrm{~m}$ beneath the surface, indicated by dashed horizontal lines in Fig. 2 (a). Only results located above the surface of 1958 are incorporated in the calculation of the deviation. Examining other firn cores, the surface of the oldest available forcing may be located at greater depth, when a density of $\rho_{c}=550 \mathrm{~kg} \mathrm{~m}^{-3}$ is already reached. In those cases the computation of the root mean square deviation is restricted to the domain showing density values smaller than $540 \mathrm{~kg} \mathrm{~m}^{-3}$. We decided to use a smaller density threshold than the critical density due to the asymptotic characteristic of the resulting density profiles using Variants 1 and 3 of the constitutive equation (Equations (14) and (16)).

As the implementation of our model is efficient and the approach is as well simple and reliable, we decided to determine the best factor $C_{\mathrm{v}_{\mathrm{i}}}$ for the four variants of the constitutive equation, by simply testing 250 values within certain ranges. These 
https://doi.org/10.5194/tc-2021-75

Preprint. Discussion started: 12 March 2021

(c) Author(s) 2021. CC BY 4.0 License.

(c) (i)

ranges are shown in Equations (18) and (19). They differ because of the inclusion or disregard of Arrhenius law, respectively. The range boundaries were determined by performing several tests.

$2.5 \times 10^{-21} \mathrm{Ks} \mathrm{m}^{2} \mathrm{~kg}^{-1} \leq C_{\mathrm{v}_{3}, \mathrm{v}_{4}} \leq 5.0 \times 10^{-15} \mathrm{Ks} \mathrm{m}^{2} \mathrm{~kg}^{-1}$

Figure 2 (b) shows the root mean square deviation (RMSD) plotted over the 250 tested values for the four different factors. The different variants are color coded and the best result is marked. The smallest value of the deviation is shown within the figure.

The corresponding density profiles are shown in Fig. 2 (a).

As can be seen in Fig. 2 (a) the firn profile of ngt03C93.2 starts at a depth of about $1.3 \mathrm{~m}$. This yields the problem of finding an appropriate surface density, needed as boundary condition in the simulation. Following our approach we tested different values of the surface density between $\rho_{0}=250 \mathrm{~kg} \mathrm{~m}^{-3}$ and $\rho_{0}=450 \mathrm{~kg} \mathrm{~m}^{-3}$, using steps of $\Delta \rho_{0}=10 \mathrm{~kg} \mathrm{~m}^{-3}$. Afterwards the best result is chosen. Overall $4 \times 250 \times 21=21000$ simulations were performed in case of ice core ngt03C 93.2 to find the optimal results shown in Fig. 2.

\section{Data}

\subsection{Firn Profiles}

In order to test the description of grain boundary sliding by Alley (1987), we use 159 firn profiles of which 80 were retrieved in Greenland. The remaining 79 measurements were taken in Antarctica. The profiles are included in the "Surface Mass Balance and Snow Depth on Sea Ice Working Group (SUMup) snow density subdataset" (Koenig and Montgomery, 2019). The dataset is available online and merges more than three thousand density measurements covering the period from 1950 to 2018 from about 180 different sources. To obtain firn profiles relevant for this study from the dataset, we filter it based on the following conditions:

1. Profiles have to consist of at least ten data points.

2. The overall length of the profiles has to exceed three meters.

3. Profiles have to start at a depth of less than three meters below surface.

4. The starting density of the profiles must not to exceed $\rho_{c}=550 \mathrm{~kg} \mathrm{~m}^{-3}$.

5. The surface mass balance at the profile locations has to be positive.

6. Forcing data of at least five years have to be available for the profile location. 
(a)

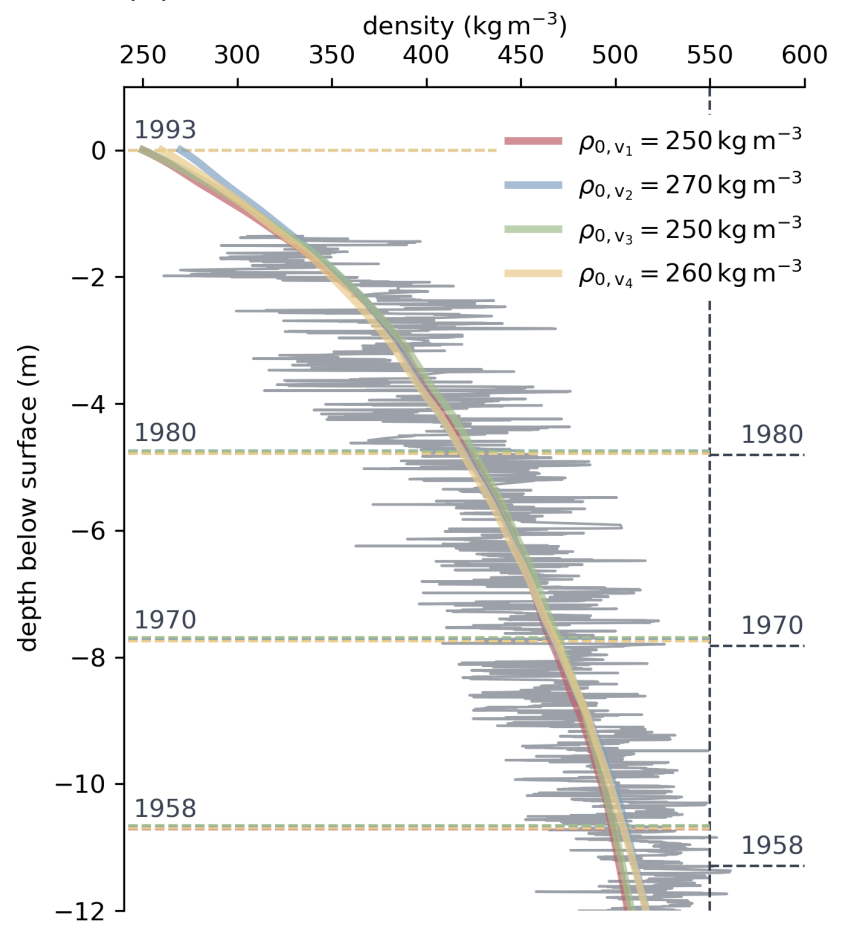

(b)

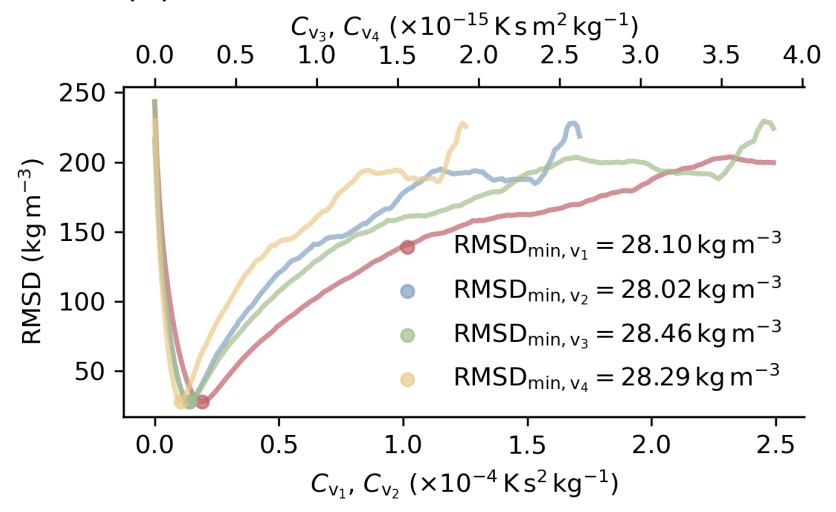

(c)

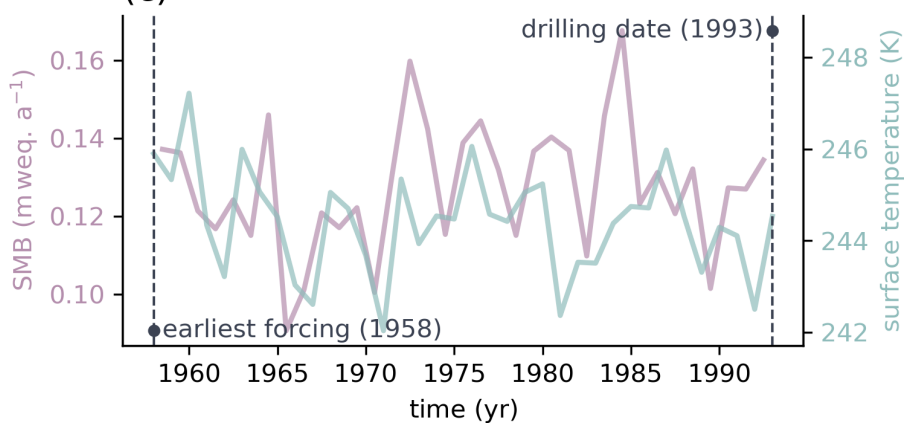

Figure 2. Panel (a) of the figure shows the depth density profile of ice core ngt03C93.2 (Wilhelms, 2000) retrieved in Greenland in gray colour and the best corresponding model results using four different variants of the constitutive law for grain boundary sliding by Alley (1987) in different colors. Dashed horizontal lines represent horizons of firn deposited in the indicated years, 1958 being the first year forcing from RACMO2.3 (Van Wessem et al., 2014; Noël et al., 2015) is available. Simulation results are drawn using colors as shown in the legend. Horizons plotted in gray, right of the vertical dashed line, represent the same surfaces as determined by Miller and Schwager (2004) during analysis of the core. Panel(b) shows the root mean square deviation between measured and modelled density plotted over the range of tested factor values. Note the different axes for different tested factors. The forcing representative for the location of ice core ngt03C 92.2 and used in the simulation is shown in panel (c). 

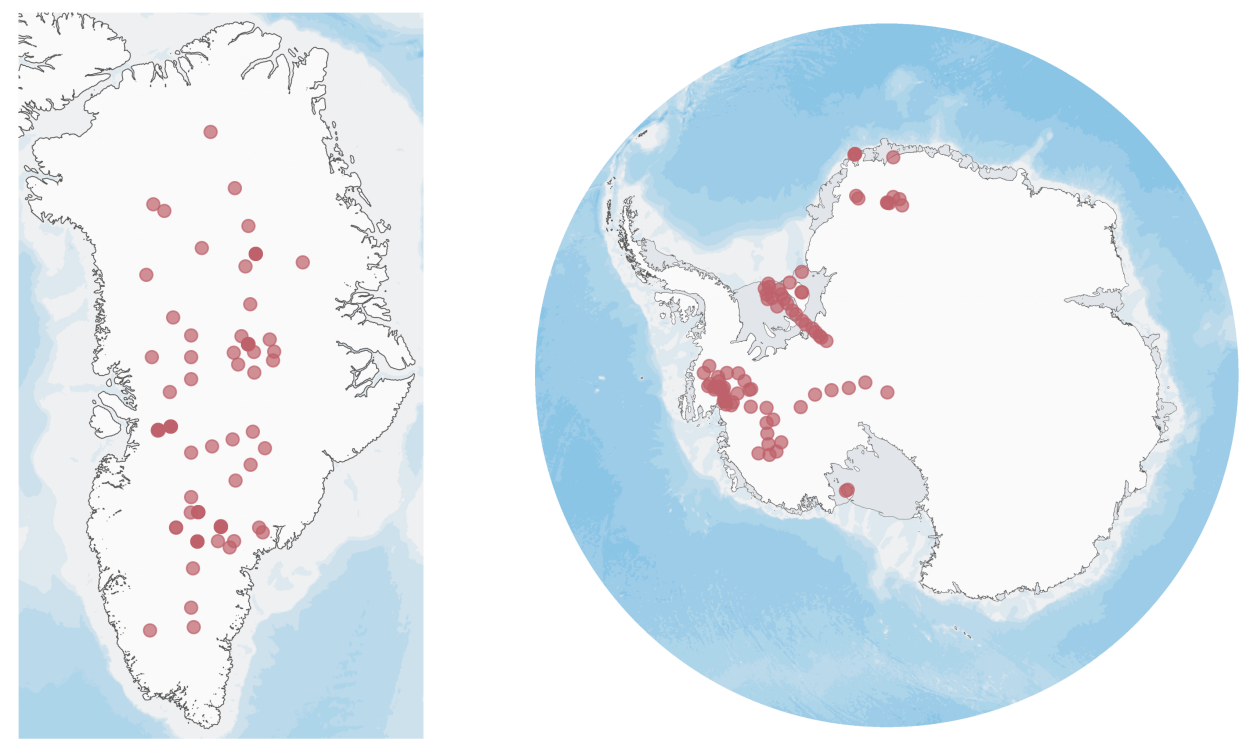

Figure 3. Locations of the firn profiles used for model comparision. 80 profiles were measured in Greenland, 79 depth density datasets were retrieved in Antarctica (map data: Amante and Eakins, 2009; Arndt et al., 2013, SCAR Antarctic Digital Database).

While criteria 1. and 2. ensure general quality of the data, conditions 3. and 4. guarantee the first stage of firn densification is incorporated. As the model is not capable of handling melt and the study focuses on dry firn densification, the surface mass balance should be positive as stated in the fifth criterion. Forcing data comes from the regional climate model RACMO2.3 (Van Wessem et al., 2014; Noël et al., 2015). This provides the surface mass balance. The model delivers data for times from 1958 to 2016 and 1979 until 2016 for Greenland and Antarctica, respectively (see also Section 5.2). Density measurements used for model comparison should thus be retrieved during this periods. We chose to only use datasets for which at least five years of forcing data is available. Furthermore a number of density profiles were excluded from the filtered data by hand. This incorporates profiles with very low spatial resolution, atypical profiles showing decreasing density with depth and measurements with a surface density very close to the critical density of $\rho_{c}=550 \mathrm{~kg} \mathrm{~m}^{-3}$. As explained in Section 4 and illustrated in Fig. 2, we only use a certain domain for the comparison between simulated and measured data. If this domain turns out to be less than $2.5 \mathrm{~m}$ long in case of any of the tested variants of the constitutive equation, the firn profile in question is neglected in the further analysis.

Figure 3 illustrates the locations from which the 159 density profiles were retrieved. The 80 measurements from Greenland are relatively evenly distributed over the ice sheet. Coastal locations though are not well covered due to the requirement of a strictly positive surface mass balance. In the Antarctic sites, locations in east Antarctica are underrepresented. However a wide variety of environments is covered, including the Filchner-Ronne Ice Shelf, the west Antarctic coast and Dronning Maud Land. 


\subsection{Boundary Conditions and Forcing}

For the forcing of the firn densification model values for surface density, surface temperature, accumulation rate and surface grain size at the locations of the measured firn profiles (Section 5.1) are needed. We use the regional climate model RACMO2.3 (Van Wessem et al., 2014; Noël et al., 2015) for this purpose. In case of Greenland RACMO2.3 provides annual data from 1958 to 2016. At every location of a measured depth density profile we interpolate the mean annual skin temperature and surface mass balance during this time period from fields available for this study with mean spatial resolutions of $11.3 \mathrm{~km}$ and $1.0 \mathrm{~km}$ respectively. At Antarctic sites the available data covers a time period from 1979 until 2016 with annual resolution. The mean spatial resolution is $8.0 \mathrm{~km}$ in case of the skin temperature and $28.5 \mathrm{~km}$ for the surface mass balance.

The time period for transient simulation runs, as described in Section 4, is specified by the earliest data available from RACMO2.3 and the drilling date of the firn core in question. In case of ice core ngt03C93.2 (Wilhelms, 2000), which was retrieved in central Greenland in 1993, the simulation time covers the period from 1958 to 1993 (see Fig. 2 (c)). Constant values of the surface temperature and surface mass balance for the preceding spin up are calculated as mean values over this time range.

As pointed out in Section 4 we use 21 surface density values in the range of $250 \mathrm{~kg} \mathrm{~m}^{-3} \leq \rho_{0} \leq 450 \mathrm{~kg} \mathrm{~m}^{-3}$ for every tested firn profile. The value leading to the best result is then used for further analysis. Due to the lack of relevant data, simplicity and better comparison options the grain size at the surface is assumed to be the same at every location and to be constant over time. We chose to use a grain radius of $r_{0}=0.5 \mathrm{~mm}$.

Figure 4 illustrates the range and distribution of surface boundary conditions at the investigated sites. The distribution of the surface density values leading to the best results using the optimisation scheme within the given range, is in good agreement with characteristic values of the surface density obtained and used in other studies (Sugiyama et al., 2012; Lundin et al., 2017; Tian et al., 2018; Weinhart et al., 2020). In comparison locations in Greenland show a higher mean surface temperature and surface mass balance than locations in Antarctica. This results in lower values of the surface density in Greenland, which is plausible. In general a wide variety of typical climatic conditions for both ice sheets is covered. In order to solve for the temperature a Neumann boundary condition is used at the profile base. The first derivative of the temperature is forced to be zero.

\section{Results}

Figure 5 illustrates the distribution of the root mean square deviation (RMSD) calculated from the simulated firn profiles matching the measured profiles best. The four different plots of the figure distinguish between the four different variants of the constitutive equation for grain boundary sliding (Equations (14) to (17)) as described in Section 4. Additionally the median value of the data is shown. The differences in the distribution of the deviation are small with regard to the different tested variants. The median values differ in a small range. Variant 2 shows the smallest value and Variant 3 the greatest. The use of the modification introduced by Bréant et al. (2017) within the constitutive equation results in $6.2-6.8 \%$ better agreement between simulated and measured firn profiles. To put the values in perspective, the deviation of the four best fitting modelled 

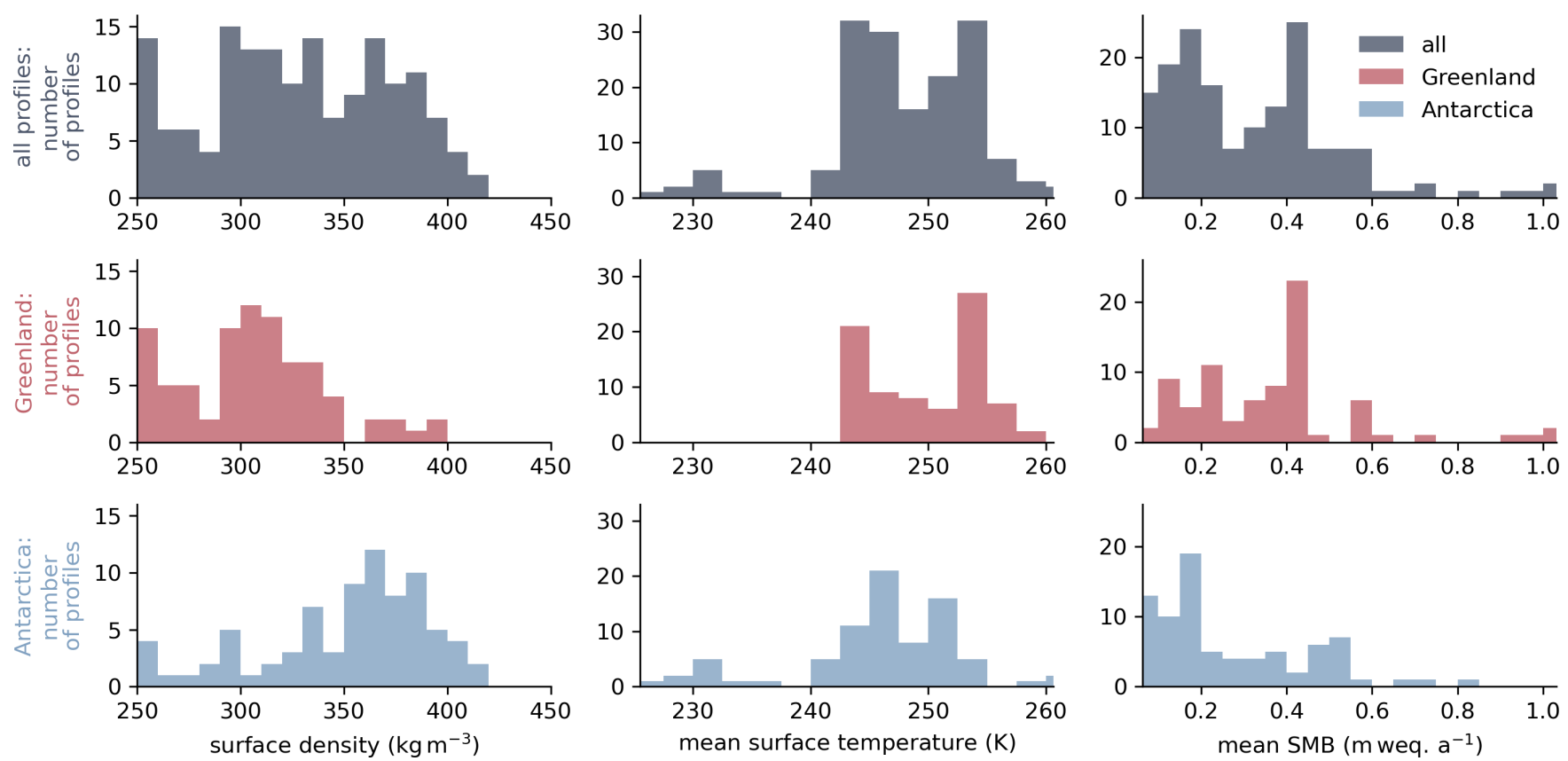

Figure 4. Distribution and comparison of the boundary conditions at the 159 firn profile sites. All values are averaged over the specific simulation time for every location, beginning in the year 1958 or 1979 respectively and ending at the date of measurement (see Section 5.2). The top row of plots, in gray colour, shows the boundary conditions at all locations, while the middle and bottom row, in red and blue, exclusively represent locations in Greenland and Antarctica. Data for the surface temperature in the middle, and surface mass balance in the right column, are provided via RACMO2.3 (Van Wessem et al., 2014; Noël et al., 2015).

firn profiles from ice core ngt03C93.2 (Wilhelms, 2000) displayed in Fig. 2 is about $28 \mathrm{~kg} \mathrm{~m}^{-3}$. That means, more than half of the resulting simulations show even better agreement with the corresponding firn density profiles than this one.

Furthermore, the example of ice core ngt03C 93.2 shows not only a good match of simulated and measured density, but also quite a good agreement to the measured age structure as illustrated by four different horizons in Fig. 2 (a). Similar results were obtained from a subsample of 40 firn profiles of which the age structure is available.

The range of factors resulting in the best fitting firn profile is smaller for Variants 2 and 4 of the constitutive equation, which use the modification by Bréant et al. (2017), compared to Variants 1 and 3, as shown in form of box plots in Fig. 6. In contrast to factors $C_{\mathrm{v}_{1}}$ and $C_{\mathrm{v}_{2}}$, factors $C_{\mathrm{v}_{3}}$ and $C_{\mathrm{v}_{4}}$ incorporate the Arrhenius law from the original description of grain boundary sliding by Alley (1987). Therefore a direct comparison between the two groups of factors is not possible. The quartile coefficient of dispersion, shown for the four variants on the right side of Fig. 6, is a relative measure for the scatter of the values. The coefficient reveals that the resulting factors of Variants 1 and 2 are defined in a range narrower versus Variants 3 and 4 . All four resulting sets of factors show a slightly non uniform distribution, tending towards smaller values. 

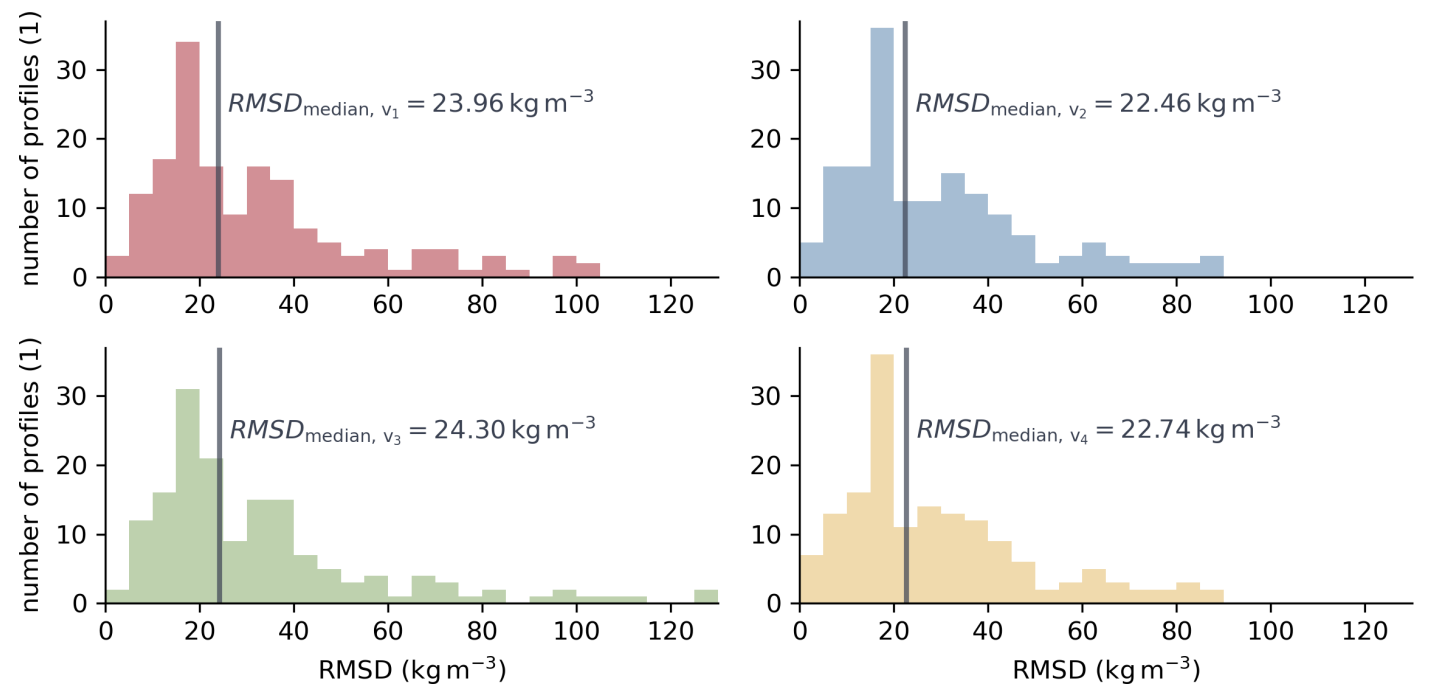

Figure 5. Distribution of the smallest root mean square deviation (RMSD) for every analysed firn profile found using the optimisation scheme outlined in Section 4. The four plots show the results for the four tested variants of the constitutive equation. Vertical lines illustrate the median value of the 159 values.
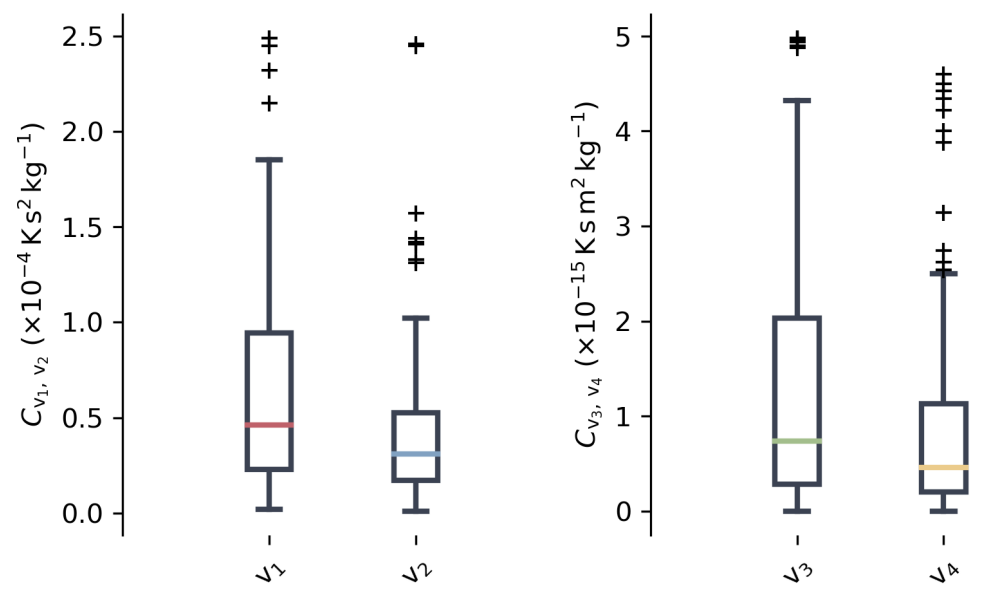

Figure 6. Box plots showing the distribution of the best factors $C_{\mathrm{v}_{1}}$ to $C_{\mathrm{v}_{4}}$ for the four variants of the constitutive equation describing grain boundary sliding (see Equations (14) to (17)), derived using the optimisation scheme described in Section 4. On the right side the quartile coefficient of dispersion $v_{\mathrm{r}}$ is shown for the variants in corresponding colors. The quartile coefficient of dispersion is calculated using the first $Q_{1}$ and third $Q_{3}$ quartile values of the data sets as shown in black colour and represents a robust relative measure of dispersion. 

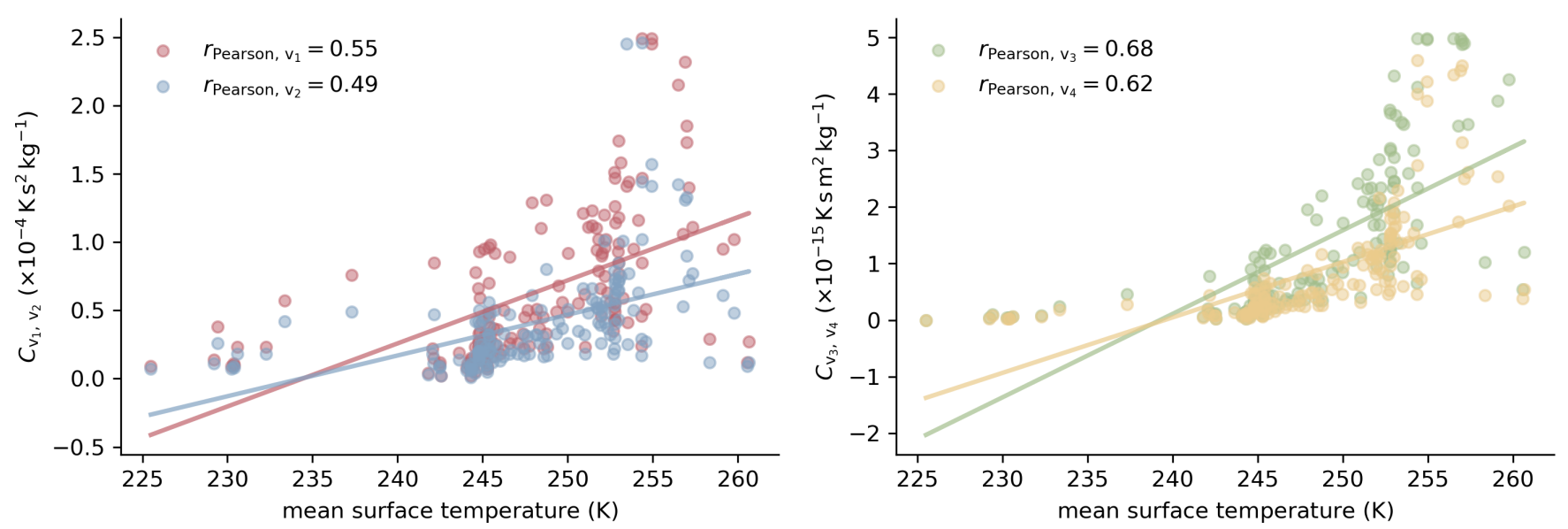

Figure 7. Best factors for every investigated firn profile, determined using the optimisation scheme, plotted against the mean surface temperature during the forcing period (see Section 4). On the left side of the figure the results for Variants 1 and 2 of the constitutive equation are shown in blue and red colour respectively, while the right plot illustrates the results of Variants 3 and 4 in green and yellow colours. Lines represent a linear fit to the data. Additionally the Pearson correlation coefficient, representing the linear correlation between factors $C_{\mathrm{v}_{1}}$ to $C_{\mathrm{v}_{4}}$ and the mean surface temperature, is given.

To find a possible dependency of the resulting factors, leading to the best match between simulated and measured density profiles, Fig. 7 shows the 159 factors found by the optimisation, plotted against the mean surface temperature calculated from the forcing data specific for each firn profile's site. The left plot illustrates the results for Variants 1 and 2 in red and blue colour, while the right part of the figure shows the resulting factors for Variants 3 and 4 using green and yellow markers respectively. Lines represent a linear fit to the four scatter plots, the legend features the Pearson correlation coefficient, a measure for the linear correlation of the two variables. The linear correlation of the resulting factors with the mean surface temperature is quite high compared to other properties. This is especially true for factors $C_{\mathrm{v}_{3}}$ and $C_{\mathrm{v}_{4}}$ of Variants 3 and 4 . However the Pearson correlation coefficient only indicate the linear correlation. The scatter of factors $C_{\mathrm{v}_{3}}$ and $C_{\mathrm{v}_{4}}$ with respect to the mean surface temperature might resemble a higher order function.

Even higher values of the Pearson correlation coefficient can be found in Fig. 8, which shows the resulting factors in the same manner as Fig. 7 but with respect to the mean surface mass balance. Just as the mean surface temperature, the mean surface mass balance is calculated from the forcing data used during the simulations. The correlation coefficients for the results of Variants 3 and 4 exceed the ones for the variants of the constitutive equation incorporating the Arrhenius law explicitly. The best indication of a linear relationship between the factor resulting in the density profile best matching the corresponding field measurement and the surface mass balance can be seen for Variant 3. 

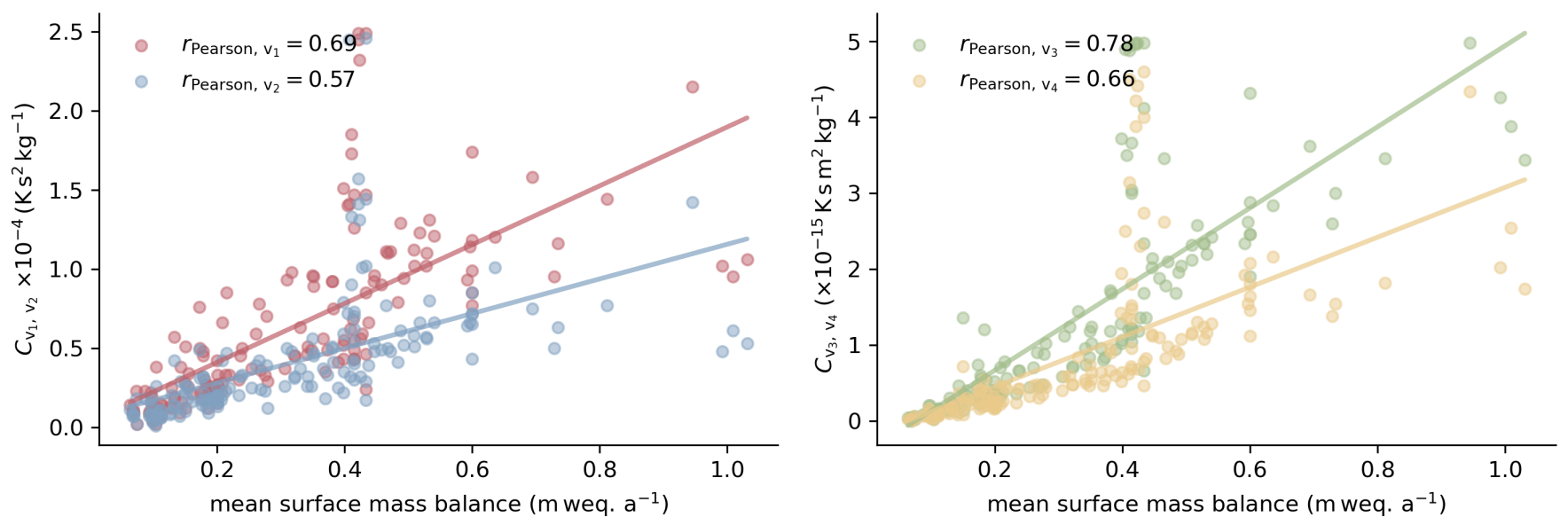

Figure 8. Resulting factors of the optimisation over the mean surface mass balance, calculated for everyone of the 159 firn profiles from its forcing. The left hand side plot shows best fitting values for factors $C_{\mathrm{v}_{1}}$ and $C_{\mathrm{v}_{2}}$. The plot on the right shows the corresponding values for Variants 3 and 4 or factors $C_{\mathrm{v}_{3}}$ and $C_{\mathrm{v}_{4}}$ respectively. The linear correlation between factors and mean surface mass balance is illustrated by a linear fit and the Pearson correlation coefficient for all four tested variants.

\section{Discussion}

Given the uncertainties in forcing, the limited knowledge on initial grain size and the poor constraint on density at the surface, we find a reasonable good match between grain boundary sliding based simulated density profiles and observed ones. If the goal of a modelling approach is to simulate the upper firn layer down to a density of $\rho_{c}=550 \mathrm{~kg} \mathrm{~m}^{-3}$ well, the description of grain boundary sliding first introduced to firn by Alley (1987) is a good basis for a physically based model. We were able to find distinct minima of the deviation between simulated and measured density profiles using the described optimisation scheme. Furthermore, the simulated firn age is in good agreement with the measurement. This indicates that not only the final state of the firn profile at the time of the measurement is well represented, but also its history. A factor often neglected in firn model development before. Unfortunately the measured age structure is only available for a rather small subset of the firn density profiles used in this study.

However, it has to be mentioned that we have not investigated whether grain boundary sliding is indeed the dominating process during the first stage of firn densification. We only assess whether a process with a functional dependence on density, firn overburden stress, temperature and grain size, is representing observed density profiles well. Any other deformation process with the same functional dependence would be equally well suited.

Comparing the results for Variants 1 and 2, as well as Variants 3 and 4 , we find that the adjustment of $\left(1-\frac{5}{3} \rho / \rho_{\text {ice }}\right)$ to $\left(1+\frac{0.5}{6}-\frac{5}{3} \rho / \rho_{\text {ice }}\right)$ is leading to better matches with measured density profiles. With regard to the study design and the background of a physics based model describing firn densification, this result has to be reviewed carefully. As Alley (1987) points out, grain boundary sliding might be the dominant process driving the firn densification at low densities, but presumably 
not the only one. The constitutive law by Alley (1987) is designed in a way that the densification due to grain boundary sliding becomes zero at the density of $\rho_{c}=550 \mathrm{~kg} \mathrm{~m}^{-3}$, motivated by densest packing of spheres and increasing accommodation incompatibilities. The modification by Bréant et al. (2017) changes this behaviour in the way that the process grain boundary sliding vanishes at a density of about $\rho_{c}^{*}=596 \mathrm{~kg} \mathrm{~m}^{-3}$, which could have advantages for the transition into the next stage of firn densification. We suggest a simultaneous decline of grain boundary sliding and increase of one or more other processes would provide a good characterisation. Namely dislocation creep drives the densification at higher density (Maeno and Ebinuma, 1983) due to increasing stresses. An onset of dislocation creep at densities lower than $\rho_{c}=550 \mathrm{~kg} \mathrm{~m}^{-3}$ affecting not necessarily the entire bulk firn matrix, but increasing volume fractions of the porous matrix should be investigated further in future.

As pointed out in Section 6 and shown in Figure 7, a considerable correlation of the resulting factors $C_{\mathrm{v}_{3}}$ and $C_{\mathrm{v}_{4}}$ with the mean surface temperature exists. The same correlation is not as high for Variants 1 and 2, in which the Arrhenius law from the description of the bond viscosity is incorporated. Also the quartile coefficient of dispersion describing the scattering of factors and shown in Fig. 6 is lower for Variants 1 and 2 compared to results of Variants 3 and 4. The additional dependency on the temperature in form of the Arrhenius law is captured within the factors $C_{\mathrm{v}_{3}}$ and $C_{\mathrm{v}_{4}}$, but results in a worse determination of these parameters. A good determination of the activation energy for boundary diffusion and the corresponding prefactor is therefore crucial for the description of grain boundary sliding.

As the mean surface temperature correlates well with the mean surface mass balance, a dependency of the resulting factors on the mean surface mass balance, as shown in Fig. 8, seems obvious. But the quite strong correlation of results from Variants 1 and 2, incorporating the additional temperature dependency in form of the Arrhenius law, and higher values of the Pearson correlation coefficient indicate a clear dependency of the resulting factors on the mean surface mass balance. We interpret the dependency of the mismatch on the surface mass balance such, that the load situation is currently not represented well. Due to the lateral confinement we expect horizontal stresses to play an increasing role with depth. The description of the load situation can only be improved solving an axially symmetrical three dimensional problem and considering further processes contributing to densification. Further interpretation of the factors resulting in the best match between simulated and measured density profiles is difficult because there exists no direct dependency on the surface mass balance in the described model.

\section{Conclusions}

Using variants of the constitutive relation for grain boundary sliding by Alley (1987) and a efficient optimisation scheme, we were able to reproduce a sample of 159 firn density profiles reasonably well. Even though available only for a rather small subsample of the analysed firn profiles, the comparison of the measured age structure to the simulation also shows good agreement. Thus we conclude, that the description of grain boundary sliding as introduced by Alley (1987) is suitable for the simulation of firn densification at low density.

In our optimisation approach we use a single factor representing various model parameters and search for the factor value leading to the best match between simulated and measured firn profiles. In this way the simulation result is independent of the possibly deficient, now substituted, model parameters. We find a linear dependency of the factors on the surface mass 
https://doi.org/10.5194/tc-2021-75

Preprint. Discussion started: 12 March 2021

(c) Author(s) 2021. CC BY 4.0 License.

(c) (i)

balance. As the amount of surface accumulation affects the load situation, we assume it is not represented well in the model. Unlike other firn densification models, the physical approach of grain boundary sliding depends not directly on the surface mass balance, but on the actual stress. Therefore, a further interpretation of the resulting factors is difficult using the presented simulation setup. Horizontal components of the stress tensor have to be evaluated in a higher dimensional model approach.

Additionally, the simulation is also limited by the used forcing data. As measured firn densities represent past climate conditions, deviant forcing would always result in a mismatch between simulated and measured firn properties, independent of the optimisation approach and physical model. Improvement of the forcing with respect to resolution in time and covering of longer periods, could lead to better simulation results in future.

We want to emphasise, that any kind optimisation approaches are only possible due to enormous efforts of the SUMup team (Koenig and Montgomery, 2019), that made a vast amount of firn core data available. This is strategically crucial for firn densification modelling advances, which adds to the recommendations of FirnMICE (Lundin et al., 2017) for enhanced efforts for physically based models.

Code availability. The code used for the simulation of firn profiles will become available via github.com and gitlab.com at the time of publication of this manuscript.

Author contributions. T.S. has developed the numerics, code, conducted and analysed all simulations. All authors have jointly developed the concept of the modelling approach, discussed the results and wrote the manuscript.

Competing interests. We declare that no competing interests are present.

Acknowledgements. This project has been funded by the German Research Foundation in the Priority Program SPP1158 under project number 403642112. We want to acknowledge the fantastic community effort SUMup, which provides a database of firn core data. We want to thank Sepp Kipfstuhl (AWI) and Johannes Freitag (AWI) for discussions on firn densification. 
https://doi.org/10.5194/tc-2021-75

Preprint. Discussion started: 12 March 2021

(c) Author(s) 2021. CC BY 4.0 License.

(c) (i)

\section{References}

Alley, R. B.: Firn Densification by Grain-Boundary-Sliding: A First Model, Journal de Physique, 48, C1-249 - C1-256, https://doi.org/https://doi.org/10.1051/jphyscol:1987135, 1987.

Amante, C. and Eakins, B. W.: ETOPO1 1 Arc-Minute Global Relief Model: Procedures, Data Sources and Analysis, NOAA Technical Memorandum NESDIS NGDC-24, National Geophysical Data Center, NOAA, 2009.

Arnaud, L., Barnola, J. M., and Duval, P.: Physical modeling of the densification of snow/firn and ice in the upper part of polar ice sheets, Phyiscs of Ice Core Records, pp. 285-305, 2000.

Arndt, J. E., Schenke, H. W., Jakobsson, M., Nitsche, F. O., Buys, G., Goleby, B., Rebesco, M., Bohoyo, F., Hong, J., Black, J., Greku, R.,

Udintsev, G., Barrios, F., Reynoso-Peralta, W., Taisei, M., and Wigley, R.: The International Bathymetric Chart of the Southern Ocean (IBCSO) Version 1.0 - A new bathymetric compilation covering circum-Antarctic waters, Geophysical Research Letters, 40, 3111-3117, https://doi.org/https://doi.org/10.1002/grl.50413, 2013.

Arthern, R. J. and Wingham, D. J.: The Natural Fluctuations of Firn Densification and their Effect on the Geodetic Determination of Ice Sheet Mass Balance, Climatic Change, 40, 605-624, https://doi.org/https://doi.org/10.1023/A:1005320713306, 1998.

Arthern, R. J., Vaughan, D. G., Rankin, A. M., Mulvaney, R., and Thomas, E. R.: In situ measurements of Antarctic snow compaction compared with predictions of models, Journal of Geophysical Research, 115, https://doi.org/https://doi.org/10.1029/2009JF001306, 2010.

Bader, H.: Sorge's Law of Densification of Snow on High Polar Glaciers, Journal of Glaciology, 2, 319-323, https://doi.org/https://doi.org/10.3189/S0022143000025144, 1954.

Bréant, C., Marinterie, P., Orsi, A., Arnaud, L., and Landais, A.: Modelling firn thickness evolution during the last deglaciation: constraints on sensitivity to temperature and impurities, Clim. Past., 13, 833-853, https://doi.org/https://doi.org/10.5194/cp-13-833-2017, 2017.

Ferziger, J. H. and Perić, M.: Computational Methods for Fluid Dynamics, Springer, Berlin, Heidelberg, New York, Barcelona, Hong Kong, London, Milan, Paris, Tokyo, 3., rev. edn., 2002.

Fourtenau, K., Gillet-Chaulet, F., Martinerie, P., and Faïn, X.: A Micro-Mechanical Model for the Transformation of Dry Polar Firn Into Ice Using the Level-Set Method, Front. Earth. Sci., 8, https://doi.org/https://doi.org/10.3389/feart.2020.00101, 2020.

Goujon, C., Barnola, J.-M., and Ritz, C.: Modeling the densification of polar firn including heat diffusion: Application to closeoff characteristics and gas isotopic fractionation for Antarctica and Greenland sites, Journal of Geophysical Research, 108, 4792, https://doi.org/https://doi.org/10.1029/2002JD003319, 2003.

Gow, A. J.: On the Rates of Growth of Grains and Crystals in South Polar Firn, Journal of Glaciology, 8, 241-252, https://doi.org/https://doi.org/10.3189/S0022143000031233, 1969.

415 Haupt, P.: Continuum Mechanics and Theory of Materials, Springer-Verlag Berlin Heidelberg New York, 2002.

Herron, M. M. and Langway, C. C.: Firn Densification: An Empirical Model, Journal of Glaciology, 25, 373-385, https://doi.org/https://doi.org/10.3189/S0022143000015239, 1980.

Johnson, J. B. and Hopkins, M. A.: Identifying microstructural deformation mechanisms in snow using discrete-element modeling, Journal of Glaciology, 51, 432-442, https://doi.org/https://doi.org/10.3189/172756505781829188, 2005.

420 Kang, S.-J. L.: Sintering, Densification, Grain Growth, and Microstructure, Butterworth-Heinemann, 2005.

Koenig, L. and Montgomery, L.: Surface Mass Balance and Snow Depth on Sea Ice Working Group (SUMup) snow density subdataset, Greenland and Antarctica, 1950-2018, Tech. rep., Arctic Data Center, https://doi.org/doi:10.18739/A26D5PB2S, 2019. 
https://doi.org/10.5194/tc-2021-75

Preprint. Discussion started: 12 March 2021

(c) Author(s) 2021. CC BY 4.0 License.

(c) (i)

Ligtenberg, S. R. M., Helsen, M. M., and van den Broeke, M. R.: An improved semi-empirical model for the densification of Antarctic firn, The Cryosphere, 5, 809-819, https://doi.org/https://doi.org/10.5194/tc-5-809-2011, 2011.

Lundin, J. M. D., Stevens, C. M., Arthern, R., Buizert, C., Orsi, A., Ligtenberg, S. R. M., Simonsen, S. B., Cummings, E., Essery, R., Leahy, W., Harris, P., Helsen, M. M., and Waddington, E. D.: Firn Model Intercomparison Experiment (FirnMICE), Journal of Glaciology, 63, 401-422, https://doi.org/https://doi.org/10.1017/jog.2016.114, 2017.

Maeno, N. and Ebinuma, T.: Pressure Sintering of Ice and Its Implications to the Densification of Snow at Polar Glaciers and Ice Sheets, J. Phys.Chem., 87, 349-365, https://doi.org/https://doi.org/10.1021/j100244a023, 1983.

Miller, H. and Schwager, M.: Accumulation rate and stable oxygen isotpoe ratios of ice core ngt03C93.2 form the North Greenland Traverse, PANGAEA, https://doi.org/https://doi.org/10.1594/PANGAEA.218274, 2004.

Noël, B., van de Berg, W. J., van Meijgaard, E., Kuipers Munneke, P., van de Wal, R. S. W., and van den Broeke, M. R.: Evaluation of the updated regional climate model RACMO2.3: summer snowfall impact on the Greenland Ice Sheet, The Cryosphere, 9, 1831-1844, https://doi.org/https://doi.org/10.5194/tc-9-1831-2015, 2015.

Paterson, W. S. B.: The Physics of Glaciers, Butterworth-Heinemann, Linacre House, Jordan Hill, Oxford OX2 8DP, 200 Wheeler Road, Birlington, MA 01803, 3rd edn., 1994.

Raj, R. and Ashby, M. F.: On Grain Boundary Sliding and Diffusional Creep, Metallurgical Transactions, 2, 1113-1127, https://doi.org/https://doi.org/10.1007/BF02664244, 1971.

Robin, G. d. Q.: Glaciology III: Seismic Shooting and Related Investigations, Norwegian-British-Swedish Antarctic Expedition, 1949-52, Scientific Results Vol. 5, Norsk Polarinstitutt, Oslo, 1958

Simonsen, S. B., Stenseng, L., Aðalsgeirsdóttir, G., Faustio, R. S., Hvidberg, S., and Lucas-Picher, P.: Assessing a multilayered dynamic firn-compaction model for Greenland with ASIRAS radar measurement, Journal of Glaciology, 59, 545-558, https://doi.org/https://doi.org/10.3189/2013JoG12J158, 2013.

Stephenson, P. J.: Some Considerations of Snow Metamorphism in the Antarctic Ice Sheet in the Light of Ice Cycle Studies, in: Physics of Snow and Ice, edited by Ōura, H., vol. 1, Part2, pp. 725-740, Hokkaido University, Institute of Low Temperature Science, Sapporo, 1967.

Sugiyama, S., Enomoto, H., Fujita, S., Fukui, K., Nakazawa, F., Holmlund, P., and Surdyk, S.: Snow density along the route traversed by the Japanese-Swedish Antarctic Expedition 2007/08, Journal of Glaciology, 58, 529-539, https://doi.org/https://doi.org/10.3189/2012JoG11J201, 2012.

Theile, T., Löwe, H., Theile, T. C., and Schneebeli, M.: Simulating creep of snow based on microstructure and the anisotropic deformation of ice, Acta Materialia, 59, 7104-7113, https://doi.org/https://doi.org/10.1016/j.actamat.2011.07.065, 2011.

Tian, Y., S., Z., Du, W., Chen, J., Xie, H., Tong, X., and Li, R.: Surface Snow Density of East Antarctica Derived from In-Situ Observations, The International Archives of the Photogrammetry, Remote Sensing and Spatial Information Sciences, XLII-3, 1657-1669, https://doi.org/https://doi.org/10.5194/isprs-archives-XLII-3-1657-2018, 2018.

Van Wessem, J. M., Reijmer, C. H., Morlighem, M., Mouginot, J., Rignot, E., Medley, B., Joughin, I., Wouter, B., Depoorter, M. A., Bambler, J. L., Lenaerts, J. T. M., Van De Berg, W. J., Van Den Broeke, M. R., and Van Meujgaard, E.: Improved representation of East Antarctic surface mass balance in a regional atmospheric climate model, Journal of Glaciology, 60, 761-770, https://doi.org/https://doi.org/10.3189/2014JoG14J051, 2014.

Verjans, V., Leeson, A. A., Nemeth, C., Stevens, C. M., Kuipers Munneke, P., Noël, B., and van Wessen, J. M.: Bayesian calibration of firn densification models, The Cryosphere, 14, 3017-3032, https://doi.org/https://doi.org/10.5194/tc-14-3017-2020, 2020. 
https://doi.org/10.5194/tc-2021-75

Preprint. Discussion started: 12 March 2021

(C) Author(s) 2021. CC BY 4.0 License.

(c) (i)

460 Weinhart, A. H., Freitag, J., Hörhold, M., Kipfstuhl, S., and Eisen, O.: Representative surface snow density on the East Antarctic Plateau, The Cryoshphere, 14, 3663-3685, https://doi.org/https://doi.org/10.5194/tc-14-3663-2020, in review, 2020.

Wilhelms, F.: Density of ice core ngt03C93.2 from the North Greenland Traverse, Pangaea, https://doi.org/https://doi.org/10.1594/PANGAEA.56560, 2000. 